\title{
Optimal stereotactic body radiotherapy dosage for hepatocellular carcinoma: a multicenter study
}

\author{
Ting-Shi Su ${ }^{1,2^{*}} \oplus$, Qiu-Hua Liu ${ }^{2}$, Xiao-Fei Zhu ${ }^{3}$, Ping Liang ${ }^{2}$, Shi-Xiong Liang ${ }^{1}$, Lin Lai ${ }^{2}$, Ying Zhou ${ }^{2}$, Yong Huang ${ }^{2}$,
} Tao Cheng ${ }^{2}$ and Le-Qun Li ${ }^{4^{*}}$

\begin{abstract}
Background: The optimal dose and fractionation scheme of stereotactic body radiation therapy (SBRT) for hepatocellular carcinoma (HCC) remains unclear due to different tolerated liver volumes and degrees of cirrhosis. In this study, we aimed to verify the dose-survival relationship to optimize dose selection for treatment of HCC.

Methods: This multicenter retrospective study included 602 patients with HCC, treated with SBRT between January 2011 and March 2017. The SBRT dosage was classified into high dose, moderate dose, and low dose levels: SaRT (BED $10 \geq 100 \mathrm{~Gy}$ ), SbRT (EQD $>74$ Gy to $\left.\mathrm{BED}_{10}<100 \mathrm{~Gy}\right)$, and ScRT (EQD $\left.2<74 \mathrm{~Gy}\right)$. Overall survival (OS), progressionfree survival (PFS), local control (LC), and intrahepatic control (IC) were evaluated in univariable and multivariable analyses.
\end{abstract}

Results: The median tumor size was $5.6 \mathrm{~cm}$ (interquartile range [IQR] $1.1-21.0 \mathrm{~cm}$ ). The median follow-up time was 50.0 months (IQR 6-100 months). High radiotherapy dose correlated with better outcomes. After classifying into the SaRT, SbRT, and ScRT groups, three notably different curves were obtained for long-term post-SBRT survival and intrahepatic control. On multivariate analysis, higher radiation dose was associated with improved OS, PFS, and intrahepatic control.

Conclusions: If tolerated by normal tissue, we recommend SaRT (BED $10 \geq 100 \mathrm{~Gy}$ ) as a first-line ablative dose or SbRT $\left(E Q D_{2} \geq 74 \mathrm{~Gy}\right.$ ) as a second-line radical dose. Otherwise, $\mathrm{SCRT}$ ( $E Q D_{2}<74 \mathrm{~Gy}$ ) is recommended as palliative irradiation.

Keywords: Hepatocellular carcinoma, Radiotherapy dosage, Stereotactic body radiotherapy, Survival rate

\section{Background}

Hepatocellular carcinoma (HCC) is highly prevalent in many Asian countries and accounts for nearly $80 \%$ of HCC cases worldwide. In China, HCC is the second most common cause of cancer-related deaths and the fourth

\footnotetext{
*Correspondence: sutingshi@163.com; Li_lequn@263.net

${ }^{1}$ Department of Radiation Oncology, Guangxi Medical University Cancer Hospital, Nanning 530001, Guangxi Zhuang Autonomous Region, China

${ }^{4}$ Department of Hepatobiliary Surgery, Guangxi Medical University

Cancer Hospital, Nanning 530021, Guangxi Zhuang Autonomous Region, China

Full list of author information is available at the end of the article
}

most commonly diagnosed cancer among men [1]. HCC is resectable in only $10-40 \%$ of newly diagnosed patients. Liver resection, transplantation, percutaneous ethanol injection, or radiofrequency ablation (RFA) are the standard treatments for early-stage HCC [2].

The use of external beam radiation therapy (RT) [3], specifically including stereotactic body radiation therapy (SBRT), is increasing in popularity of treatment for HCC [4-11]. It is commonly recommended as an alternative treatment in medically inoperable patients, as a result of its rapid adoption in clinical practice worldwide [12-14]. SBRT for primary HCC provides high rates of original author(s) and the source, provide a link to the Creative Commons licence, and indicate if changes were made. The images or other third party material in this article are included in the article's Creative Commons licence, unless indicated otherwise in a credit line to the material. If material is not included in the article's Creative Commons licence and your intended use is not permitted by statutory regulation or exceeds the permitted use, you will need to obtain permission directly from the copyright holder. To view a copy of this licence, visit http://creativecommons.org/licenses/by/4.0/. The Creative Commons Public Domain Dedication waiver (http://creativeco mmons.org/publicdomain/zero/1.0/) applies to the data made available in this article, unless otherwise stated in a credit line to the data. 
durable local control $(89-100 \%)[8,15-18]$, but there is no clear evidence of a dose-survival relationship for the commonly used radiation therapy schedules. Increasing radiotherapy dose was associated with improved overall survival in patients treated with SBRT for stage I nonsmall-cell lung cancer [19-21]. However, the optimal dose and fractionation scheme of SBRT for HCC remains unclear because primary $\mathrm{HCCs}$ tend to be associated with different degrees of cirrhosis and tolerated liver volumes. In a previous retrospective study of SBRT for 127 patients with HCCs that were $>5 \mathrm{~cm}$, we preliminarily found that higher biologically effective dose $\left(\mathrm{BED}_{10}\right)$ and equivalent dose in 2 Gy fractions $\left(\mathrm{EQD}_{2}\right)$ was associated with better survival [22]. In another prior prospective study, we built normal tissue complication probability models and nomograms for radiation-induced hepatic toxicity to obtain individual liver constraints for HCC patient [23]. In current study, we aimed to verify the dose-survival relationship to optimize dose selection for treatment of HCC.

\section{Methods}

\section{Study design and patients}

This was a multicenter retrospective study of patients with HCC who underwent SBRT in China between January 2011 and March 2017. HCC diagnosis was established based on histopathology or according to the clinical criteria for diagnosis of HCC [13]. The eligibility criteria were as follows: primary or recurrent/residual HCC patients, who were medically inoperable or refused to undergo surgery and radiofrequency ablative therapy, treated with SBRT. The exclusion criteria were as follows: (a) prior history of abdominal conventional radiotherapy, (b) intrahepatic cholangiocellular carcinoma, (c) gallbladder metastases, and/or (d) liver metastases, (e) patients with incomplete data and lost to follow-up.

\section{Stereotactic body radiation therapy}

Briefly, the patients were immobilized with a customized external vacuum-type. All patients were treated using the CyberKnife system (Accuray Incorporated, Sunnyvale, CA, USA), with $6 \mathrm{Mv}$ photons. Three or four gold markers were inserted into the surrounding area of the tumor or into tumor tissue. Gross tumor volume was delineated as the visible tumor. Planning target volume was established as a $0-5 \mathrm{~mm}$ expansion of the GTV. No internal target volume was created because tracking was used. A dose of 28-55 Gy was administered in 1-6 fractions on consecutive days at the $50-85 \%$ isodose line that covered at least $97 \%$ of the planning target volume. Total doses and fractionation schedules were chosen according to size and dose-volume constraints of the organs at risk. The SBRT technique used has been previously described $[5,17,22-24]$

\section{Response evaluation and follow-up}

Patients were re-evaluated 1 month after SBRT and every 3-6 months thereafter. In addition, contrast-enhanced CT or/and MRI were performed at each follow-up visit. The Modified RECIST Response Evaluation Criteria in Solid Tumors (mRECIST) guideline was used to evaluate the response of the tumor [25]. The laboratory examinations assessed levels of aspartate transaminase (AST), alanine transaminase (ALT), prothrombin time (PT), levels of albumin, total bilirubin, alpha fetoprotein (AFP).

\section{Calculated values}

$\mathrm{BED}_{10}$ and $E Q D_{2}$ were assumed at an $\alpha / \beta$ ratio of 10 , for rapidly proliferating tumor cells. EQD was calculated as: $\mathrm{d} \times \mathrm{n}\{(\alpha / \beta+\mathrm{d}) /(\alpha / \beta+\mathrm{dx})\}$; BED was calculated as: $\mathrm{d} \times \mathrm{n}\{1+\mathrm{d} /(\alpha / \beta)\} ; \quad(\mathrm{d}=$ dose, $\mathrm{n}=$ fraction and $\mathrm{dx}=2)$. Based on our previous studies [22, 23], the SBRT dosage was classified into high dose, moderate dose, and low dose levels: SaRT (BED $10 \geq 100 \mathrm{~Gy})$, SbRT (EQD ${ }_{2}>74 \mathrm{~Gy}$ to $\left.\mathrm{BED}_{10}<100 \mathrm{~Gy}\right)$, and ScRT (EQD $\left.{ }_{2}<74 \mathrm{~Gy}\right)$.

\section{Statistical analysis}

Overall survival (OS), progression-free survival (PFS) incidence of local recurrence (LC), and incidence of intrahepatic recurrence (IC) rates were estimated using the Kaplan-Meier method and compared between groups using the log-rank test. Cumulative OS was calculated starting from the date of the first treatment until the date of the final follow-up or death. Cumulative PFS was calculated starting from the date of the first treatment until the date of recurrence or progression or death. LC was calculated starting from the date of the first treatment until the date of local recurrence or progression. IC was calculated starting from the date of the first treatment until the date of intrahepatic recurrence or progression.

Additionally, variables without associations between each other were analyzed by chi-squared/Mann-Whitney-tests. We use univariate with significant value $(P<0.05)$ to identify non-associated predictive variables that contribute towards the final multivariate. For categorical variables, the Pearson's chi-squared test was used. Kruskal-Wallis test was used to analyze continuous variables.

All statistical analyses were performed using $\mathrm{R}$ version 4.0.2 (2020-06-22) software. $P<0.05$ was considered statistically significant. 


\section{Results}

Baseline characteristics

A total of 602 HCC patients with complete information were included in this study. All patients were classified into three groups according to SBRT dosage: SaRT $(\mathrm{n}=259)$, SbRT $(\mathrm{n}=163)$, and ScRT $(\mathrm{n}=180)$. The demographic and clinical characteristics of the patients and their treatment are summarized in Table 1. We observed strong associations between RT dose/fractionation and other prognostic factors, including BCLC class, tumor size, and ALBI grade. In general, patients with small tumors, BCLC stage A, and/or low ALBI score received higher RT doses, whereas those with larger tumors, BCLC B, C, D, and/or higher ALBI score received lower RT doses.

\section{Clinical effectiveness of increasing radiation dose}

The median tumor size was $5.6 \mathrm{~cm}$ (interquartile range [IQR] 1.1-21.0 cm). The median follow-up time was 50.0 months (IQR 6-100 months). When RT dose was used to classify the patients into the SaRT, SbRT, and ScRT groups, 3 notably different curves were observed for long-term post-SBRT survival.

The 1-, 2-, 3-, and 5-year OS rates were 81.4, 64.9, 54.1, and $46.4 \%$ in the SaRT group; $67.7,39.5,33.3$, and $28 \%$ in the SbRT group; and 50.0, 28.7, 24.0, and $11.1 \%$ in the ScRT group, respectively (log-rank $P<0.0001$; Fig. 1a).

The 1-, 2-, 3-, and 5-year PFS rates were 59.6, 41.8, 34.3 and $21.5 \%$ in the SaRT group; 39.5, 22.6, 13.8, and 7.2\% in the SbRT group; and 22.5, 10.3, 9.3, and 5.2\% in the ScRT group, respectively (log-rank $P<0.0001$; Fig. 1b).

The 1-, 2-, 3-, and 5-year LC rates were 82.5, 73.7, 65.9 and $57.9 \%$ in the SaRT group; 80.6, 63.5, 57.5 and $57.5 \%$ in the SbRT group; and 67.2, 55.5, 50.9 and $40.7 \%$ in the ScRT group, respectively ( $\log$-rank $P=0.00594$; Fig. $1 c)$.

The 1-, 2-, 3-, and 5-year IC rates were 69.7, 58.7, 50.1 and $36.0 \%$ in the SaRT group; 59.1, 42.5, 31.4 and $23.9 \%$ in the SbRT group; and 41.2, 27.6, 25.9 and $20.7 \%$ in the ScRT group, respectively (log-rank $P<0.0001$; Fig. $1 d)$.

\section{Multivariable Cox analysis}

Cox proportional hazards models accounting for clustering were used to compare the SaRT, SbRT, and ScRT groups. The selection of influencing factors without associations between each other, including: age, gender, hepatitis B virus (HBV) status, AFP, PT, AST, ALT, alkaline phosphatase (ALP), albumin-bilirubin (ALBI) score, RT dose, recurrence/residual disease, Barcelona Clinic Liver Cancer (BCLC) stage, and tumor size, were considered for multivariate analysis based on $P$ value $<0.05$ in univariable analyses.
Multivariable cox regression analysis of OS (Fig. 2a) showed that 6 independent predictors were RT dosage (SbRT/SaRT: $H R=1.34,95 \%$ CI 1.06-1.7; $P=0.015$; ScRT/SaRT: HR =1.67, 95\% CI 1.32-2.1; $P<0.001)$, ALBI score, BCLC stage, HBV, AST, and AFP level $>400$.

Multivariable cox regression analysis of PFS (Fig. 2b) showed that 5 independent predictors were RT dosage (SbRT/SaRT: HR $=1.43,95 \%$ CI $1.08-1.9 ; P=0.014$; ScRT/SaRT: HR $=1.68,95 \%$ CI 1.27-2.2; $P<0.001)$, ALBI score, BCLC stage, HBV, and tumor size.

Multivariable cox regression analysis of LC (Fig. 2c) showed that BCLC stage was an only independent predictor.

Multivariable cox regression analysis of IC (Fig. 2d) showed that 2 independent predictors were RT dosage (SbRT/SaRT: HR $=1.25$, 95\% CI 0.92-1.7; $P=0.15$; ScRT/ SaRT: $H R=1.60,95 \%$ CI $1.12-2.2 ; P=0.004)$ and BCLC stage.

\section{Subgroup analysis of total dose and fractionation scheme for OS and PFS}

Additionally, we found a significant association between higher total dose (TD) and better OS. The 1 -, 3-, and 5-year OS rates were 70.6, 46.0, and $37.8 \%$ in the $\mathrm{TD} \geq 42$ Gy group and 55.1, 28.9, and $12.9 \%$ in the $\mathrm{TD}<42$ Gy group, respectively (log-rank $P<0.001$; Fig. 3a). The 1-, 3-, and 5-year PFS rates were 46.8, 31.7, and $14.0 \%$ in the $\mathrm{TD} \geq 42$ Gy group and $35.8,17.1$, and $7.8 \%$ in the $\mathrm{TD}<42$ Gy group, respectively (log-rank $P<0.001$; Fig. 3b).Further, patients treated with single fraction $(n=6)$ and 2 fractions group $(n=7)$ were excluded (Additional file 1: Supplementary Fig. S1), we found that the use of fewer fractions ( $=3$ fractions) group was association with significantly better OS (Fig. 3c) and PFS (Fig. 3d) than more fractions ( $\geq 4$ to 6 fractions) group.

Additionally, a sensitivity analysis excluding the initial 127 overlapping patients [22], three notably different curves were also obtained for long-term post-SBRT survival for log-rank testing among the high, moderate and low dose groups (Additional file 1: Supplementary material Figure S2-3).

\section{Discussion}

Precise SBRT dose is important but uncertain, especially in $\mathrm{HCC}$ that can be treated with radical radiotherapy, because primary HCCs tend to be associated with different tolerated liver volumes and degrees of cirrhosis. In the current study, we classified radiotherapy doses into high dose, moderate dose, and low dose levels: SaRT $\left(\mathrm{BED}_{10} \geq 100 \mathrm{~Gy}\right)$, SbRT $\left(\mathrm{EQD}_{2}>74 \mathrm{~Gy}\right.$ to $\left.\mathrm{BED}_{10}<100 \mathrm{~Gy}\right)$, and ScRT (EQD $\left.2<74 \mathrm{~Gy}\right)$. Three notably different curves were obtained for long-term post-SBRT 
Table 1 Patient and treatment characteristics for different dose groups

\begin{tabular}{|c|c|c|c|c|c|}
\hline Factor & Level & SaRT & SbRT & ScRT & $P$ value \\
\hline $\mathrm{N}$ & & 259 & 163 & 180 & \\
\hline \multirow[t]{2}{*}{ Gender } & Female & $38(14.7 \%)$ & $23(14.1 \%)$ & $24(13.3 \%)$ & 0.92 \\
\hline & Male & $221(85.3 \%)$ & $140(85.9 \%)$ & $156(86.7 \%)$ & \\
\hline Age, median (IQR) & & $54(45,64)$ & $55(45,63)$ & $51(44,58.5)$ & 0.030 \\
\hline \multirow[t]{2}{*}{ Age $\geq 60$} & No & $164(63.3 \%)$ & $105(64.4 \%)$ & $137(76.1 \%)$ & 0.012 \\
\hline & Yes & $95(36.7 \%)$ & $58(35.6 \%)$ & $43(23.9 \%)$ & \\
\hline \multirow[t]{3}{*}{ HBV } & Positive & $188(72.6 \%)$ & 115 (70.6\%) & $123(68.3 \%)$ & 0.17 \\
\hline & Negative & $33(12.7 \%)$ & $25(15.3 \%)$ & $38(21.1 \%)$ & \\
\hline & Unknown & $38(14.7 \%)$ & $23(14.1 \%)$ & $19(10.6 \%)$ & \\
\hline \multirow[t]{5}{*}{ AFP status } & $0-8$ & $80(30.9 \%)$ & $38(23.3 \%)$ & $35(19.4 \%)$ & $<0.001$ \\
\hline & $8-200$ & 95 (36.7\%) & $40(24.5 \%)$ & $41(22.8 \%)$ & \\
\hline & $200-400$ & $16(6.2 \%)$ & $8(4.9 \%)$ & $11(6.1 \%)$ & \\
\hline & $>400$ & $56(21.6 \%)$ & $68(41.7 \%)$ & $86(47.8 \%)$ & \\
\hline & Unknown & $12(4.6 \%)$ & $9(5.5 \%)$ & $7(3.9 \%)$ & \\
\hline PT, median (IQR) & & $13.3(12.7,14.3)$ & $13.4(12.6,14.2)$ & $13.15(12.5,14.25)$ & 0.58 \\
\hline INR, median (IQR) & & $1.11(1.05,1.2)$ & $1.12(1.05,1.2)$ & $1.1(1.045,1.215)$ & 0.86 \\
\hline Tbil, median (IQR) & & $13.7(9.6,19.5)$ & $14(10,21.5)$ & $14.1(9.85,20.75)$ & 0.58 \\
\hline Dbil, median (IQR) & & $5.3(3.7,8.7)$ & $6.3(4.1,10.7)$ & $6.4(4.5,10.45)$ & 0.012 \\
\hline albumin, median (IQR) & & $38(34.2,41.7)$ & $36.9(33.5,40.1)$ & $35.95(31.8,39.4)$ & $<0.001$ \\
\hline AST, median (IQR) & & $32(23,48)$ & $37(25,55)$ & $41.5(26,59.5)$ & 0.005 \\
\hline ALT, median (IQR) & & $31(21,43)$ & $31(20,46)$ & $32.5(23.5,49.5)$ & 0.31 \\
\hline ALP, median (IQR) & & $86(67,120)$ & $101(78,142)$ & $111(87.5,151.5)$ & $<0.001$ \\
\hline ALBI score, median (IQR) & & $-2.52(-2.83,-2.10)$ & $-2.38(-2.70,-2.04)$ & $-2.28(-2.62,-1.93)$ & $<0.001$ \\
\hline \multirow[t]{3}{*}{ ALBI grade } & 1 & $113(43.6 \%)$ & $59(36.2 \%)$ & $47(26.1 \%)$ & 0.002 \\
\hline & 2 & $137(52.9 \%)$ & $92(56.4 \%)$ & $123(68.3 \%)$ & \\
\hline & 3 & $9(3.5 \%)$ & $12(7.4 \%)$ & $10(5.6 \%)$ & \\
\hline \multirow[t]{3}{*}{ CTP class } & A & $212(81.9 \%)$ & $131(80.4 \%)$ & $139(77.2 \%)$ & 0.63 \\
\hline & B & $45(17.4 \%)$ & $30(18.4 \%)$ & $37(20.6 \%)$ & \\
\hline & C & $2(0.8 \%)$ & $2(1.2 \%)$ & $4(2.2 \%)$ & \\
\hline \multirow[t]{2}{*}{$\mathrm{TD} \geq 42 \mathrm{~Gy}$} & No & $13(5.0 \%)$ & $69(42.3 \%)$ & $73(40.6 \%)$ & $<0.001$ \\
\hline & Yes & $246(95.0 \%)$ & $94(57.7 \%)$ & 107 (59.4\%) & \\
\hline \multirow[t]{6}{*}{ Fractions } & 1 & $6(2.3 \%)$ & $0(0.0 \%)$ & $0(0.0 \%)$ & $<0.001$ \\
\hline & 2 & $6(2.3 \%)$ & $1(0.6 \%)$ & $0(0.0 \%)$ & \\
\hline & 3 & $230(88.8 \%)$ & $68(41.7 \%)$ & $44(24.4 \%)$ & \\
\hline & 4 & $11(4.2 \%)$ & $86(52.8 \%)$ & $85(47.2 \%)$ & \\
\hline & 5 & $6(2.3 \%)$ & $7(4.3 \%)$ & $47(26.1 \%)$ & \\
\hline & 6 & $0(0.0 \%)$ & $1(0.6 \%)$ & $4(2.2 \%)$ & \\
\hline Per dose, median (IQR) & & $15(14,15)$ & $11.5(11.125,13)$ & $10.5(9,10.625)$ & $<0.001$ \\
\hline \multirow[t]{2}{*}{ Recurrence/residual disease } & No & $137(52.9 \%)$ & $83(50.9 \%)$ & $72(40.0 \%)$ & 0.022 \\
\hline & Yes & $122(47.1 \%)$ & $80(49.1 \%)$ & $108(60.0 \%)$ & \\
\hline \multirow[t]{4}{*}{ BCLC stage } & A & $139(53.7 \%)$ & $45(27.6 \%)$ & $30(16.7 \%)$ & $<0.001$ \\
\hline & B & $57(22.0 \%)$ & $42(25.8 \%)$ & $39(21.7 \%)$ & \\
\hline & C & $60(23.2 \%)$ & $74(45.4 \%)$ & $107(59.4 \%)$ & \\
\hline & $\mathrm{D}$ & $3(1.2 \%)$ & $2(1.2 \%)$ & $4(2.2 \%)$ & \\
\hline Tumor size, median (IQR) & & $3.7(2.5,6)$ & $6(4,9.4)$ & $8.1(5.45,11)$ & $<0.001$ \\
\hline
\end{tabular}

AFP, alpha fetal protein; ALBI, albumin-bilirubin score; ALT, alanine aminotransferase; AST, aspartate aminotransferase; BCLC, Barcelona Clinic Liver Cancer; HBV, hepatitis B virus; INR, International Normalized Ratio; PT, prothrombin time; 


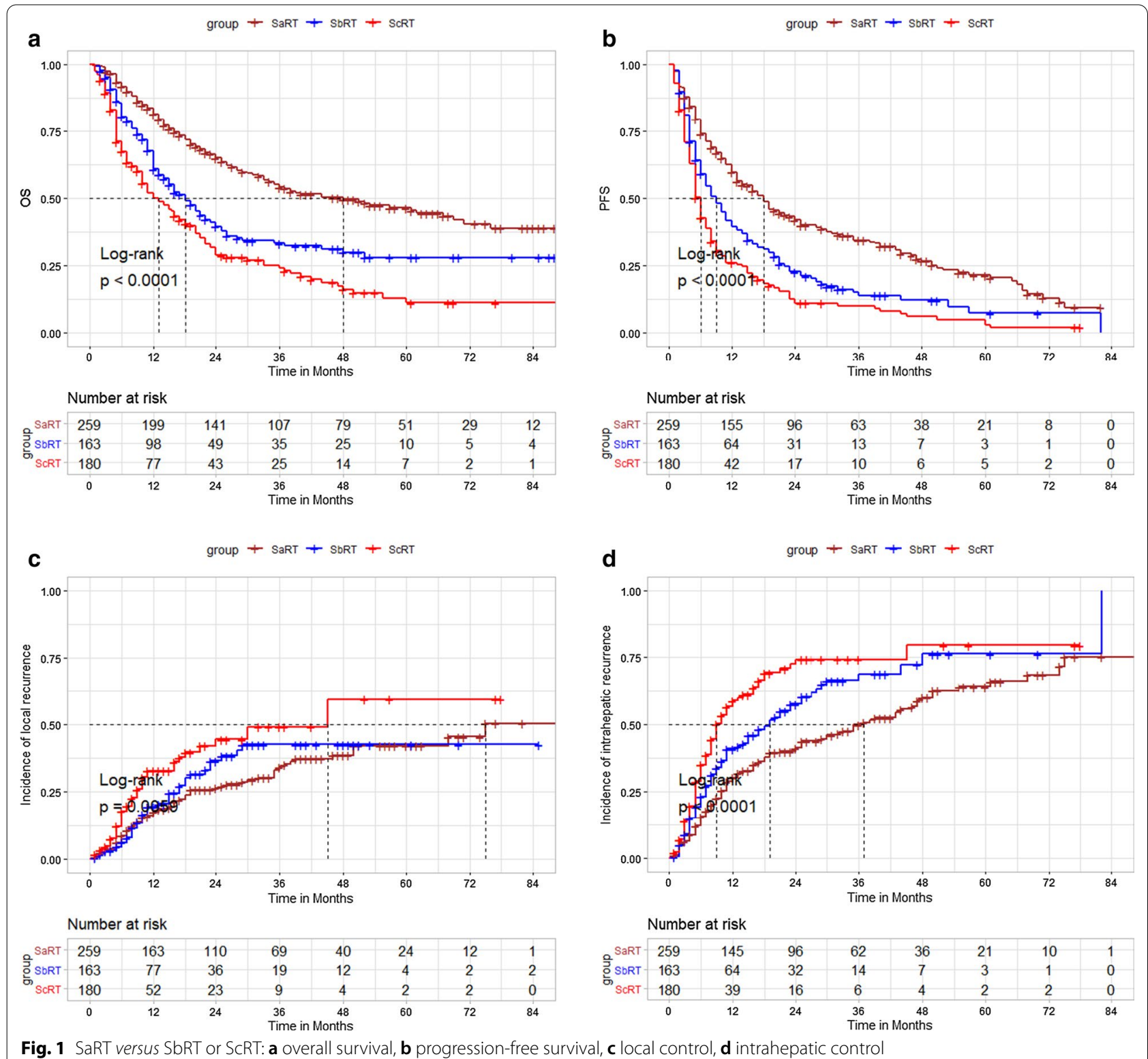

Fig. 1 SaRT versus SbRT or ScRT: a overall survival, b progression-free survival, c local control, d intrahepatic control

survival and intrahepatic control. On multivariate analysis, higher RT dose was associated with improved OS, PFS, and intrahepatic control but not local control. This finding is consistent with a previous study of SBRT for 127 patients with HCCs that were $>5 \mathrm{~cm}[22]$.

In the current study, $a \geq 42$ Gy total dose and 3 fractions were important indices that were associated with clinical curative effect (e.g. in 42 Gy in 3 fractions, $\mathrm{BED}_{10}=100.8 \mathrm{~Gy}$ and $\mathrm{EQD}_{2}=84.0 \mathrm{~Gy}$ ).Wahl et al. [16] reported that SBRT appears to be a reasonable first-line treatment for inoperable large HCC. They found no significant difference in OS between the SBRT and RFA groups, and also observed that, for tumors sized $\geq 2 \mathrm{~cm}$,
SBRT was superior to RFA in terms of freedom from local progression. In contrast, Rajyaguru et al. [26] reported 5-year OS rates of $19.3 \%$ in the SBRT group and $29.8 \%$ in the RFA group, and 60 of the 235 (26\%) received lower radiation doses (<40 Gy) in SBRT group, a followup analysis of patients receiving ablative doses (>40 Gy) showed no OS difference in comparison with patients receiving RFA [27]. Jang et al. [28] reported SBRT doses escalated from $33 \mathrm{~Gy}$ in 3 fractions to $60 \mathrm{~Gy}$ in 3 fractions for HCC (longest diameter $\leq 7 \mathrm{~cm}$ ). The 2-year OS rates for patients treated with doses $>54 \mathrm{~Gy}, 45-54 \mathrm{~Gy}$, and $<45$ Gy were $71 \%, 64 \%$, and $30 \%$, respectively, while the 2 -year local control rates were $100 \%, 78 \%$, and $64 \%$, 


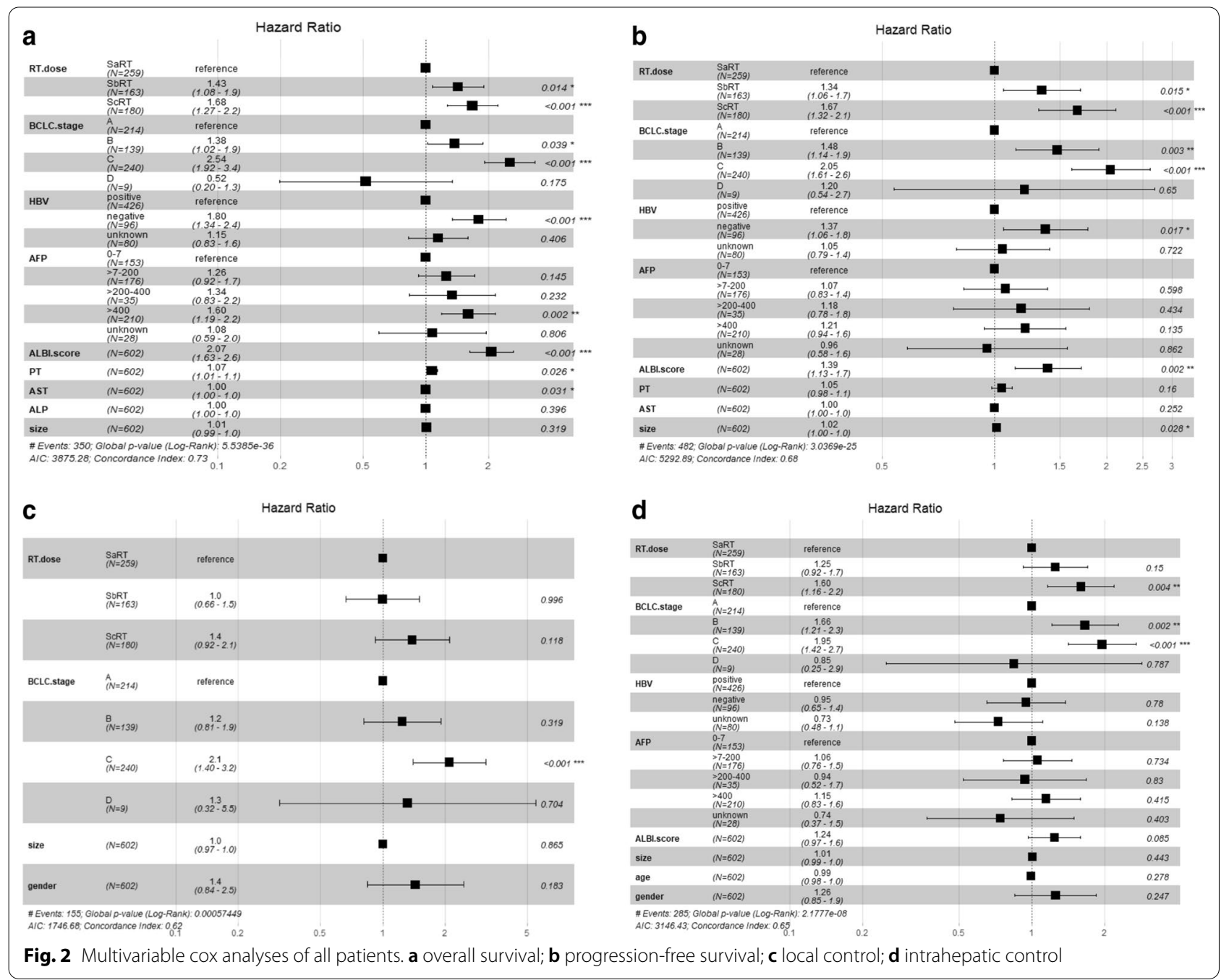

respectively. Recently, a fractionated scheme of $45 \mathrm{~Gy}$ in 3 fractions $\left(\mathrm{BED}_{10}=112.5\right.$ Gy and $\left.\mathrm{EQD}_{2}=93.8 \mathrm{~Gy}\right)$ was tested in a multi-institutional, single-arm phase II trial of SBRT for the treatment of 74 HCC patients with unifocal liver tumors within $\leq 5 \mathrm{~cm}$ in diameter in China. Thirteen patients presented with grade $\geq 2$ hepatic adverse reaction and 8 patients presented with decreased CP classification [29]. Another scheme, involving 3-5 fractions of $39-50$ Gy $\left(\mathrm{EQD}_{2}=70.0\right.$ Gy to $\left.\mathrm{BED}_{10}=112.5 \mathrm{~Gy}\right)$, has recently been tested in our single-institutional phase II trial of SBRT for the treatment of HCC in patients with a total diameter $<10 \mathrm{~cm}$. A first-line ablative dose of SaRT with a $\mathrm{BED}_{10} \geq 100 \mathrm{~Gy}$ or a second-line radical dose of SbRT with an $\mathrm{EQD}_{2} \geq 74$ Gy was recommended. Otherwise, palliative irradiation via ScRT with $\mathrm{EQD}_{2}<74$ Gy was recommended. In this prior prospective study, 85 patients have been previously reported. None case of classic radiation-induced liver disease was observed. Regarding the Child-Pugh (CP) scores following SBRT,
$20(23.5 \%)$ and $12(14.2 \%)$ patients suffered Child-Pugh scores $\mathrm{CP}+\geq 1$ and $\geq 2$, respectively. We further found that pre- $\mathrm{CP}, \mathrm{V}_{15}$ (the percentage of normal liver volume receiving more than $15 \mathrm{~Gy}$ ) and $\mathrm{VS}_{10}$ (the absolute normal liver volume spared from at least $10 \mathrm{~Gy}$ ) were optimal predictors for radiation-induced hepatic toxicity (RIHT: $C P+\geq 1$ and $\geq 2$ ) modelling and nomograms based on normal tissue complication probability (NTCP) models were generated [23]. On the basis of these two studies, optimal selection of SBRT dosage and dose-volume constraints for the liver was recommended to balance the pros and cons (Table 2).

The present study has some limitations. First, the calculation of $\mathrm{BED}_{10}$ using an $\alpha / \beta$ ratio of 10 from the linear-quadratic model is controversial, despite being commonly used. $\mathrm{BED}_{10}$ can serve as a simple and straightforward means to perform a comparative and effective analysis among a large variety of dose fractionations prescribed. The clinical efficacy of higher $\mathrm{BED}_{10}$ 

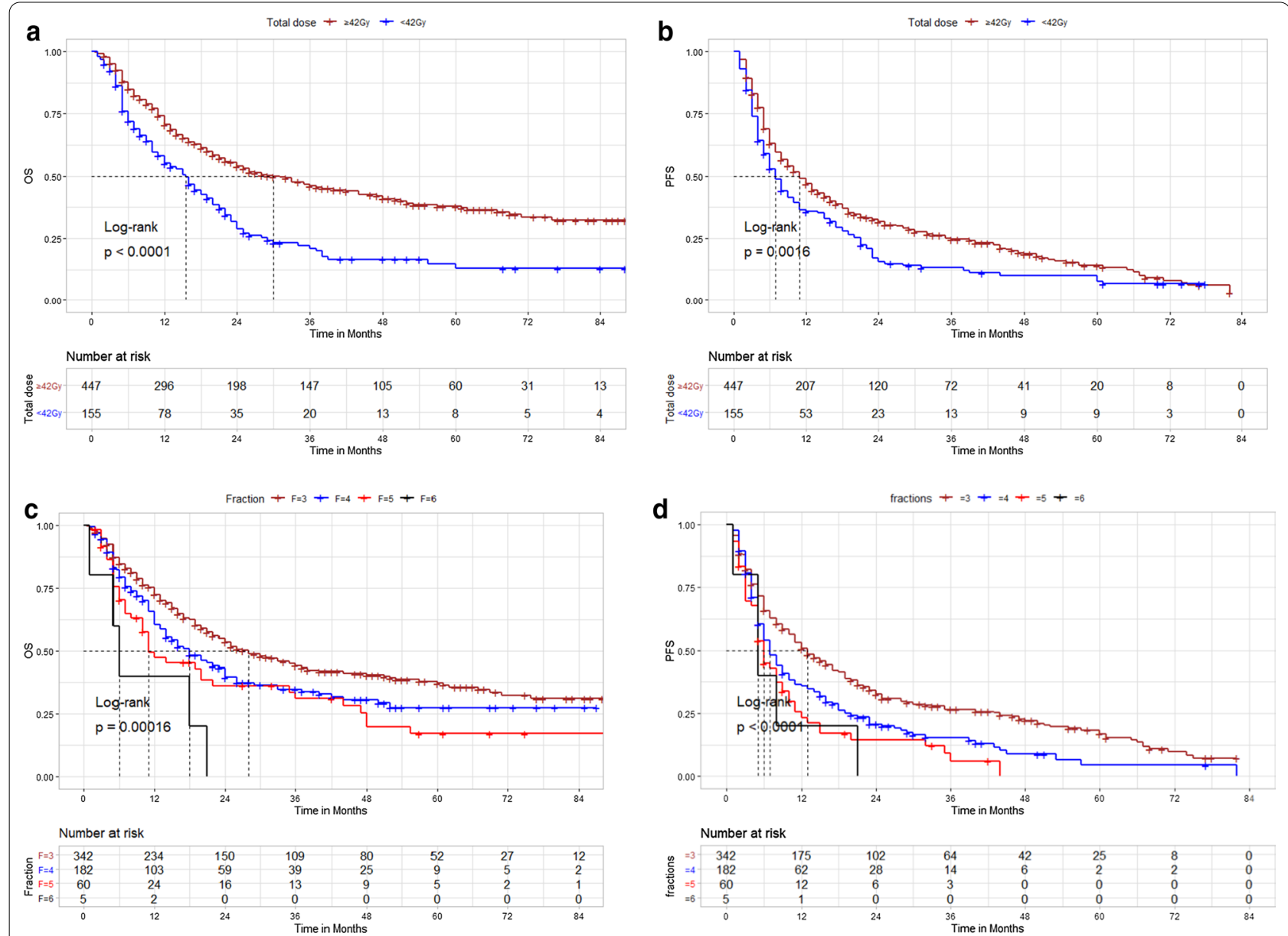

Fig. 3 a Overall survival: total doses $\geq 42$ Gy versus $<42$ Gy group; $\mathbf{b}$ progression-free survival: total doses $\geq 42$ Gy versus $<42$ Gy group; c overall survival: fractions $=3$ versus $\geq 4-6$ fractions group; $\mathbf{d}$ progression-free survival: fractions $=3$ versus $\geq 4-6$ fractions group

Table 2 Recommendations for 3-5 fractions SBRT treatment

\begin{tabular}{|c|c|}
\hline Dosimetric constraints for normal liver & Radiation dose for GTV \\
\hline $\mathrm{V}_{15}<21.5 \%, \mathrm{VS}_{10} \geq 621.8 \mathrm{~mL}$ & SaRT: $\mathrm{BED}_{10} \geq 100 \mathrm{~Gy}$ \\
\hline$V_{15}<33.1 \%, V_{10} \geq 416.2-621.8 \mathrm{~mL}$ & SbRT: EQD $2 \geq 74$ Gy \\
\hline $\begin{array}{l}\text { Without above conditions or Child-Pugh } \geq B 7 \\
\text { class }\end{array}$ & ScRT: EQD $2<74$ Gy \\
\hline
\end{tabular}

GTV, gross tumor volume; $V_{15}$, percentage of normal liver volume receiving more than $15 \mathrm{~Gy} ; \mathrm{VS}_{10}$, absolute normal liver volume spared from at least $10 \mathrm{~Gy}$

values has been fully recognized in the use of SBRT for lung cancer [19-21] and live cancer [30, 31]. Conventional radiation dose is difficult to exceed 60-74 Gy in $\mathrm{HCC}$, and we found that $\mathrm{EQD}_{2} \geq 74$ Gy was the second-line radical dose in $\mathrm{BED}_{10}<100 \mathrm{~Gy}$. Second, this study was performed in an area in which hepatitis $B$ is endemic; it is unclear whether the dosimetric findings are applicable to cases of $\mathrm{HCC}$ associated with other risk factors.
In conclusion, higher radiotherapy doses were associated with better survival in patients undergoing SBRT for the treatment of HCC. If tolerated by normal tissue, we recommend SaRT with $\mathrm{BED}_{10} \geq 100 \mathrm{~Gy}$ as the first-line ablative dose or undergoing SbRT with $\mathrm{EQD}_{2} \geq 74$ Gy as the second-line radical dose. Otherwise, ScRT with $\mathrm{EQD}_{2}<74$ Gy is recommended as palliative irradiation. Future prospective research is warranted to validate the effects of this treatment regimen.

\section{Abbreviations}

ALBI: Albumin-bilirubin; ALT: Alanine aminotransferase; AST: Aspartate aminotransferase; BCLC: Barcelona Clinic Liver Cancer; BED: Biologically effective dose; CT: Computed tomography; CTP: Child-Turcotte-Pugh; EQD2: Equivalent dose in 2 Gy fractions; HCC: Hepatocellular carcinoma; HBV: Hepatitis B virus; IC: Intrahepatic control; LC: Local control; MRI: Magnetic resonance imaging; OS: Overall survival; PFS: Progression-free survival; RT: Radiation therapy; SBRT: Stereotactic body radiotherapy. 


\section{Supplementary Information}

The online version contains supplementary material available at https://doi. org/10.1186/s13014-021-01778-6.

Additional file 1. Fig S1: Overall survival based on different fractions. Fig S2: A sensitivity analysis excluding the initial 127 overlapping patients,three notably different curves of long-term post-SBRT survival: S2A) OS, S2A) PFS.

\section{Acknowledgements}

None.

\section{Authors' contributions}

Su made substantial contributions to conception and design of the study and the analysis and interpretation of the data. Su, Liu, Zhu, Liang P, Zhou, Lai, Cheng and Huang made substantial contributions to data acquisition. Su and Zhu participated in drafting the article. All authors participated in revising it critically for important intellectual content. All authors provided final approval of the version to be published.

\section{Funding}

This research was supported by the National Natural Science Foundation of China (81903257 and 81960534), and Guangxi Natural Science Foundation (CN) (2020GXNSFAA297171), and National Science and Technology Major Special Project (2017ZX10203207), and China International Medical FoundationTumor Precise Radiotherapy Spark Program (2019-N-11-01), and High-level innovation team and outstanding scholar program in Guangxi Colleges and Universities, and Guangxi Medical University Training Program for Distinguished Young Scholars, and Guangxi BaGui Scholars'Special Fund.

\section{Availability of data and materials}

The datasets generated during the current study are not publicly available due to hospital secrets but are available from the corresponding author (Su, sutingshi@163.com) on reasonable request.

\section{Declarations}

\section{Ethics approval and consent to participate}

The study was approved by the Institutional Ethics Committee of Guangxi Medical University Cancer Hospital (LW2019038), and informed consent was waived because of the retrospective nature of this study.

\section{Consent for publication}

Not applicable.

\section{Competing interests}

The authors declare no conflict of interest.

\begin{abstract}
Author details
${ }^{1}$ Department of Radiation Oncology, Guangxi Medical University Cancer Hospital, Nanning 530001, Guangxi Zhuang Autonomous Region, China. 2 Department of Radiation Oncology, Rui Kang Hospital, Guangxi Traditional Chinese Medical University, Nanning 530001, Guangxi Zhuang Autonomous Region, China. ${ }^{3}$ Department of Radiation Oncology, Changhai Hospital Affiliated To Navy Medical University, Shanghai, China. ${ }^{4}$ Department of Hepatobiliary Surgery, Guangxi Medical University Cancer Hospital, Nanning 530021, Guangxi Zhuang Autonomous Region, China.
\end{abstract}

Received: 30 December 2020 Accepted: 1 March 2021 Published online: 21 April 2021

\section{References}

1. Chen W, Zheng R, Baade PD, Zhang S, Zeng H, Bray F, Jemal A, Yu XQ, He J. Cancer statistics in China, 2015. CA Cancer J Clin. 2016:66(2):115-32.
2. European Association For The Study of The L, European Organisation For $\mathrm{R}$, Treatment of C: EASL-EORTC clinical practice guidelines: management of hepatocellular carcinoma. J Hepatol. 2012, 56(4):908-943.

3. Su TS, Li LQ, Meng WW, Wang YD, Chen YT, Li JX, Du YQ, Qu S, Zhao C, Huang DJ, et al. Long-term survival analysis of transarterial chemoembolization plus radiotherapy vs. radiotherapy for hepatocellular carcinoma with macroscopic vascular invasion. Front Oncol. 2020;10:1205

4. Durand-Labrunie J, Baumann AS, Ayav A, Laurent V, Boleslawski E, Cattan S, Bogart E, Le Deley MC, Steen V, Lacornerie T, et al. Curative irradiation treatment of hepatocellular carcinoma: a multicenter phase 2 trial. Int J Radiat Oncol Biol Phys. 2020;107(1):116-25.

5. Su TS, Liang P, Liang J, Lu HZ, Jiang HY, Cheng T, Huang Y, Tang Y, Deng X. Long-term survival analysis of stereotactic ablative radiotherapy versus liver resection for small hepatocellular carcinoma. Int J Radiat Oncol Biol Phys. 2017;98(3):639-46.

6. Sapir E, Tao Y, Schipper MJ, Bazzi L, Novelli PM, Devlin P, Owen D, Cuneo KC, Lawrence TS, Parikh ND, et al. Stereotactic body radiation therapy as an alternative to transarterial chemoembolization for hepatocellular carcinoma. Int J Radiat Oncol Biol Phys. 2018;100(1):122-30.

7. Su TS, Liang P, Zhou Y, Huang Y, Cheng T, Qu S, Chen L, Xiang BD, Zhao C, Huang DJ, et al. Stereotactic body radiation therapy vs. transarterial chemoembolization in inoperable barcelona clinic liver cancer stage a hepatocellular carcinoma: a retrospective, propensity-matched analysis. Front Oncol. 2020;10:347.

8. Sanuki N, Takeda A, Oku Y, Mizuno T, Aoki Y, Eriguchi T, Iwabuchi S, Kunieda E. Stereotactic body radiotherapy for small hepatocellular carcinoma: a retrospective outcome analysis in 185 patients. Acta Oncol. 2014;53(3):399-404.

9. Sun J, Wang Q, Hong ZX, Li WG, He WP, Zhang T, Zhang AM, Fan YZ, Sun $Y Z$, Zheng $L$, et al. Stereotactic body radiotherapy versus hepatic resection for hepatocellular carcinoma $(</=5 \mathrm{~cm})$ : a propensity score analysis. Hepatol Int. 2020;14(5):788-97.

10. Takeda A, Sanuki N, Tsurugai Y, Iwabuchi S, Matsunaga K, Ebinuma H, Imajo K, Aoki Y, Saito H, Kunieda E. Phase 2 study of stereotactic body radiotherapy and optional transarterial chemoembolization for solitary hepatocellular carcinoma not amenable to resection and radiofrequency ablation. Cancer. 2016;122(13):2041-9.

11. Yoon SM, Kim SY, Lim Y-S, Kim KM, Shim JH, Lee D, An J, Jung J, Kim JH, Lee HC: Stereotactic body radiation therapy for small $(\leq 5 \mathrm{~cm})$ hepatocellular carcinoma not amenable to curative treatment: results of a singlearm, phase II clinical trial. Korean J Hepatol 2020, 0(0):0-0.

12. Vogel A, Cervantes A, Chau I, Daniele B, Llovet J, Meyer T, Nault JC, Neumann U, Ricke J, Sangro B, et al. Hepatocellular carcinoma: ESMO Clinical Practice Guidelines for diagnosis, treatment and follow-up. Ann Oncol. 2018;29(Supplement_4):iv238-55.

13. Zhou J, Sun HC, Wang Z, Cong WM, Wang JH, Zeng MS, Yang JM, Bie P, Liu LX, Wen TF, et al. Guidelines for diagnosis and treatment of primary liver cancer in China liver (2017 Edition). Cancer. 2018;7(3):235-60.

14. Benson AB 3rd, D'Angelica MI, Abbott DE, Abrams TA, Alberts SR, Saenz DA, Are C, Brown DB, Chang DT, Covey AM, et al. NCCN guidelines insights: hepatobiliary cancers, version 1.2017. J Natl Compr Canc Netw. 2017;15(5):563-73.

15. Bibault JE, Dewas S, Vautravers-Dewas C, Hollebecque A, Jarraya $H_{\text {, }}$ Lacornerie T, Lartigau E, Mirabel X. Stereotactic body radiation therapy for hepatocellular carcinoma: prognostic factors of local control, overall survival, and toxicity. PLoS ONE. 2013;8(10):e77472.

16. Wahl DR, Stenmark MH, Tao Y, Pollom EL, Caoili EM, Lawrence TS, Schipper MJ, Feng M. Outcomes after stereotactic body radiotherapy or radiofrequency ablation for hepatocellular carcinoma. J Clin Oncol. 2016;34(5):452-9.

17. Su TS, Liang P, Lu HZ, Liang J, Gao YC, Zhou Y, Huang Y, Tang MY, Liang $J N$. Stereotactic body radiation therapy for small primary or recurrent hepatocellular carcinoma in 132 Chinese patients. J Surg Oncol. 2016;113(2):181-7.

18. Huertas A, Baumann AS, Saunier-Kubs F, Salleron J, Oldrini G, CroiseLaurent V, Barraud H, Ayav A, Bronowicki JP, Peiffert D. Stereotactic body radiation therapy as an ablative treatment for inoperable hepatocellular carcinoma. Radiother Oncol. 2015;115(2):211-6.

19. Koshy M, Malik R, Weichselbaum RR, Sher DJ. Increasing radiation therapy dose is associated with improved survival in patients undergoing 
stereotactic body radiation therapy for stage I non-small-cell lung cancer. Int J Radiat Oncol Biol Phys. 2015;91(2):344-50.

20. Kestin L, Grills I, Guckenberger M, Belderbos J, Hope AJ, WernerWasik M, Sonke JJ, Bissonnette JP, Xiao Y, Yan D, et al. Dose-response relationship with clinical outcome for lung stereotactic body radiotherapy (SBRT) delivered via online image guidance. Radiother Oncol. 2014;110(3):499-504.

21. Onishi H, Shirato H, Nagata Y, Hiraoka M, Fujino M, Gomi K, Niibe Y, Karasawa K, Hayakawa K, Takai Y, et al. Hypofractionated stereotactic radiotherapy (HypoFXSRT) for stage I non-small cell lung cancer: updated results of 257 patients in a Japanese multi-institutional study. J Thorac Oncol. 2007;2(7 Suppl 3):S94-100.

22. Su TS, Lu HZ, Cheng T, Zhou Y, Huang Y, Gao YC, Tang MY, Jiang HY, Lian $\mathrm{ZP}$, Hou EC, et al. Long-term survival analysis in combined transarterial embolization and stereotactic body radiation therapy versus stereotactic body radiation monotherapy for unresectable hepatocellular carcinoma $>5 \mathrm{~cm}$. BMC Cancer. 2016;16(1):834.

23. Su TS, Luo R, Liang P, Cheng T, Zhou Y, Huang Y. A prospective cohort study of hepatic toxicity after stereotactic body radiation therapy for hepatocellular carcinoma. Radiother Oncol. 2018;129(1):136-42.

24. Su TS, Yang HM, Zhou Y, Huang Y, Liang P, Cheng T, Chen L, Li LQ, Liang SX. Albumin - bilirubin (ALBI) versus Child-Turcotte-Pugh (CTP) in prognosis of HCC after stereotactic body radiation therapy. Radiat Oncol. 2019;14(1):50.

25. Lencioni R, Llovet JM. Modified RECIST (mRECIST) assessment for hepatocellular carcinoma. Semin Liver Dis. 2010;30(1):52-60.

26. Rajyaguru DJ, Borgert AJ, Smith AL, Thomes RM, Conway PD, Halfdanarson TR, Truty MJ, Kurup AN, Go RS. Radiofrequency ablation versus stereotactic body radiotherapy for localized hepatocellular carcinoma in nonsurgically managed patients: analysis of the national cancer database. J Clin Oncol. 2018:36(6):600-8.

27. Shinde A, Jones BL, Chen YJ, Amini A. Radiofrequency ablation versus stereotactic body radiotherapy for localized hepatocellular carcinoma: does radiation dose make a difference? J Clin Oncol. 2018;36(24):2566-7.

28. Jang W, Kim M, Bae S, Cho C, Yoo H, Seo Y, Kang J, Kim S, Lee D, Han C, et al. High-dose stereotactic body radiotherapy correlates increased local control and overall survival in patients with inoperable hepatocellular carcinoma. Radiat Oncol. 2013;8:250.

29. Liu X, Song Y, Liang P, Su T, Zhang H, Zhao X, Yuan Z, Wang P. Analysis of the factors affecting the safety of robotic stereotactic body radiation therapy for hepatocellular carcinoma patients. Onco Targets Ther. 2017;10:5289-95.

30. Scorsetti M, Comito T, Cozzi L, Clerici E, Tozzi A, Franzese C, Navarria P, Fogliata A, Tomatis S, D'Agostino G, et al. The challenge of inoperable hepatocellular carcinoma (HCC): results of a single-institutional experience on stereotactic body radiation therapy (SBRT). J Cancer Res Clin Oncol. 2015;141(7):1301-9.

31. Sun J, Zhang T, Wang J, Li W, Zhang A, He W, Zhang D, Li D, Ding J, Duan $X$. Biologically effective dose (BED) of stereotactic body radiation therapy (SBRT) was an important factor of therapeutic efficacy in patients with hepatocellular carcinoma $(</=5 \mathrm{~cm})$. BMC Cancer. 2019;19(1):846.

\section{Publisher's Note}

Springer Nature remains neutral with regard to jurisdictional claims in published maps and institutional affiliations.
Ready to submit your research? Choose BMC and benefit from:

- fast, convenient online submission

- thorough peer review by experienced researchers in your field

- rapid publication on acceptance

- support for research data, including large and complex data types

- gold Open Access which fosters wider collaboration and increased citations

- maximum visibility for your research: over $100 \mathrm{M}$ website views per year

At BMC, research is always in progress.

Learn more biomedcentral.com/submissions 